\title{
Eficácia do glufosinato de amônio associado com outros herbicidas na cultura
}

$$
\text { do algodão Liberty Link }{ }^{\circledR 1}
$$

\section{Ammonium-glufosinate effectiveness associated with other herbicides in Liberty Link ${ }^{\circledR}$ cotton crop}

\author{
Ronei Ben ${ }^{2}$; Miriam Hiroko Inoue ${ }^{3}$; Natan Ramos Cavalcante ${ }^{2}$; Kassio Ferreira Mendes ${ }^{4}$; \\ Rivanildo Dallacort ${ }^{3}$; Elielton Germano dos Santos ${ }^{2}$
}

Resumo - Objetivou-se com este trabalho avaliar a eficiência do glufosinato de amônio em programas de manejo de plantas daninhas no algodoeiro para a cultivar FiberMax 966 Liberty Link $^{\circledR}$. O experimento foi instalado na área experimental da Fazenda Paiaguás, localizada no município de Diamantino-MT. O experimento foi realizado em delineamento de blocos ao acaso com 8 tratamentos e 4 repetições. Para o manejo eficiente de plantas daninhas na cultivar FiberMax 966 LL, o emprego de um tratamento herbicida em pré-emergência pode reduzir até duas aplicações em pós-emergência sem que haja perdas significativas na produção, desde que o tratamento em pré-emergência seja eficiente. Caso a aplicação de um tratamento herbicida em pré-emergência não seja possível, a utilização de três aplicações sequenciais de glufosinato de amônio $\left(0,5 ; 0,4 ; 0,6 \mathrm{~kg} \mathrm{ha}^{-1}\right)$ aos 10,25 e 40 dias após emergência da cultura (DAE) resultaram em resultados semelhantes. Nas condições em que o experimento foi realizado, todos os tratamentos herbicidas foram seletivos à cultura, não sendo constatadas diferenças significativas no número de capulhos e na produtividade.

Palavras-chaves: aplicação sequencial, Gossypium hirsutum, planta daninha, transgênico

Abstract - The objective of this study was to evaluate the efficiency of ammonium-glufosinate in management programs for weeds in cotton crop FiberMax 966 Liberty Link $^{\circledR}$ genotype. The experiment was installed in experimental area of Paiaguás Farm, located in municipality of Diamantino, Mato Grosso State. The experiment was conducted in a randomized block design with eight treatments and four replications. For weeds efficient management in FiberMax 966 LL genotype, the application of herbicide treatment in pre-emergence may reduce up to two postemergence applications with no significant losses in production, but the pre-emergence treatment needs to be effective. If the application of a herbicide treatment in pre-emergence is not possible, the use of three sequential applications of ammonium-glufosinate $\left(0.5,0.4,0.6 \mathrm{~kg} \mathrm{ha}^{-1}\right)$ at 10,25 and 40 days after crop emergence (DAE) result in similar information. In the conditions that the experiment was conducted, all herbicide treatments were selective to the crop, without significant differences in bolls number and yield.

Keywords: sequential application, Gossypium hirsutum, weed, transgenic

\footnotetext{
${ }^{1}$ Recebido para publicação em 17/07/2012 e aceito em 10/12/2012.

${ }^{2}$ Discentes do curso de Agronomia da Universidade do Estado de Mato Grosso (UNEMAT), Rodovia MT 358, Km

7, CEP: 78300-000, Tangará da Serra, MT. Email: <roneiben@ @otmail.com>. (Autor para correspondência).

${ }^{3}$ Docentes do Departamento de Agronomia da Universidade do Estado de Mato Grosso (UNEMAT).

${ }^{4}$ Doutorando do Programa de Pós-Graduação em Ciências da Universidade de São Paulo (USP), Piracicaba, SP.
} 


\section{Introdução}

Segundo o levantamento da Conab, na safra 2011/2012 houve um incremento de $67,6 \%$ em área plantada com algodão no país, o que em valor absoluto representam 564,6 mil hectares a mais do que a área cultivada na safra 2009/2010. Particularmente o Estado de Mato se destaca como o principal produtor de algodão, com incremento de 69\% em área plantada (Conab, 2011).

O sucesso em uma lavoura de algodão depende de vários fatores, tais como o manejo de pragas, doenças e plantas daninhas. De acordo com Santos et al. (2011), o algodoeiro como qualquer planta cultivada em um sistema sustentável, não se desenvolve isoladamente, mas com plantas de sua espécie e de espécies diferentes, em populações com diversos espaçamentos e intimamente relacionadas. Neste sentido, Freitas et al. (2006) relatam que o controle inadequado das plantas daninhas pode afetar tanto a quantidade como a qualidade da fibra de algodão produzida. Contudo, reduções de 60 e $90 \%$ da produtividade do algodoeiro, ocorrem em função da ausência de controle de plantas daninhas (Webster et al., 2009).

Assim, no modelo atual de exploração da cultura no Brasil, o controle químico por meio de herbicidas é o mais utilizado devido à rapidez e à eficiência, e, em muitos casos, por ser o método mais econômico (Yamashita et al., 2008).

Dentro deste contexto, uma das alternativas tecnológicas mais recentes para controlar as plantas daninhas no algodoeiro é adotar o cultivo de variedades resistentes a herbicidas. No Brasil, foram liberados seis eventos de algodão geneticamente modificados, dentre eles o Liberty Link ${ }^{\circledR}$ (LL), resistente ao herbicida glufosinato de amônio (Anuário Brasileiro do Algodão, 2010).

No entanto, por se tratar de uma tecnologia recente, há carência de dados referentes ao manejo de plantas daninhas no sistema LL, principalmente no Estado de Mato Grosso. $\mathrm{O}$ fato se torna ainda mais importante visto que o sistema Liberty Link ${ }^{\circledR}$ encontra-se em ampla adoção no Mato Grosso, evidenciando a grande necessidade de buscar dados concretos referentes ao manejo de plantas daninhas no sistema LL.

Diante do exposto, objetivou-se avaliar a eficiência do glufosinato de amônio em programas de manejo de plantas daninhas no algodoeiro para a cultivar FiberMax 966 Liberty Link ${ }^{\circledR}$.

\section{Material e Métodos}

O experimento foi instalado na Fazenda Paiaguás, pertencente ao Grupo SLC Agrícola, localizada no município de Diamantino-MT, na latitude $14^{\circ} 04^{\prime} 25^{\prime}$ ' S e longitude $37^{\circ} 26^{\prime} 45^{\prime}$ ' $\mathrm{O}$. $\mathrm{O}$ experimento foi realizado entre os meses de janeiro e julho de 2011 e as características físico-químicas do solo estão na Tabela 1. A área do experimento estava sendo cultivada há mais de 15 anos com plantios sucessivos de soja e algodão.

Tabela 1. Características físico-químicas de uma amostra de solo da área em que o experimento foi realizado. Diamantino, MT. 2010/2011

\begin{tabular}{|c|c|c|c|c|c|c|c|c|c|}
\hline \multicolumn{2}{|c|}{ pH } & \multirow[t]{2}{*}{$\mathbf{A l}^{3+}$} & \multirow{2}{*}{\multicolumn{2}{|c|}{$\mathbf{H}^{+}+\mathbf{A l}^{3+}$}} & \multirow{2}{*}{\multicolumn{2}{|c|}{$\begin{array}{l}\mathrm{Ca}^{+2}+\mathrm{Mg}^{2+} \\
-\left(\mathrm{cmol}_{\mathrm{c}} \mathrm{dm}^{-3}\right)\end{array}$}} & \multirow{2}{*}{\multicolumn{2}{|c|}{$\mathrm{Ca}^{2+}$}} & \multirow[t]{2}{*}{$\mathbf{K}^{+}$} \\
\hline$\left(\mathrm{CaCl}_{2}\right)$ & $\left(\mathbf{H}_{2} \mathbf{O}\right)$ & & & & & & & & \\
\hline 4,9 & 5,5 & 0,0 & & 0 & 4,6 & & & 7 & 0,1 \\
\hline $\begin{array}{c}\mathbf{P} \\
\left(\mathrm{mg} \mathrm{dm}^{-3}\right)\end{array}$ & $\begin{array}{c}\text { M.O } \\
\left(\mathrm{g} \mathrm{dm}^{-3}\right)\end{array}$ & $\begin{array}{c}\mathrm{V} \\
(\%)\end{array}$ & B & $\begin{array}{l}\mathrm{Fe} \\
-(\mathrm{c}\end{array}$ & $\begin{array}{l}M n \\
\left.I_{c} \mathbf{d m}^{-3}\right)\end{array}$ & $\mathbf{C u}$ & $\mathbf{Z n}$ & Areia & $\begin{array}{c}\text { Silte } \\
\left(\mathrm{g} \mathrm{kg}^{-1}\right)\end{array}$ \\
\hline 20,0 & 3,8 & 58,8 & 0,3 & 249,0 & 1,5 & 1,8 & 9,0 & 315,0 & $147,0 \quad 538,0$ \\
\hline
\end{tabular}

Fonte: Laboratório Agro Análise, Cuiabá, MT. 
Os dados diários de precipitação pluviométrica, temperatura mínima e máxima do ar foram coletados em estação meteorológica localizada próxima à área durante todo o período de realização do experimento (Figura 1).

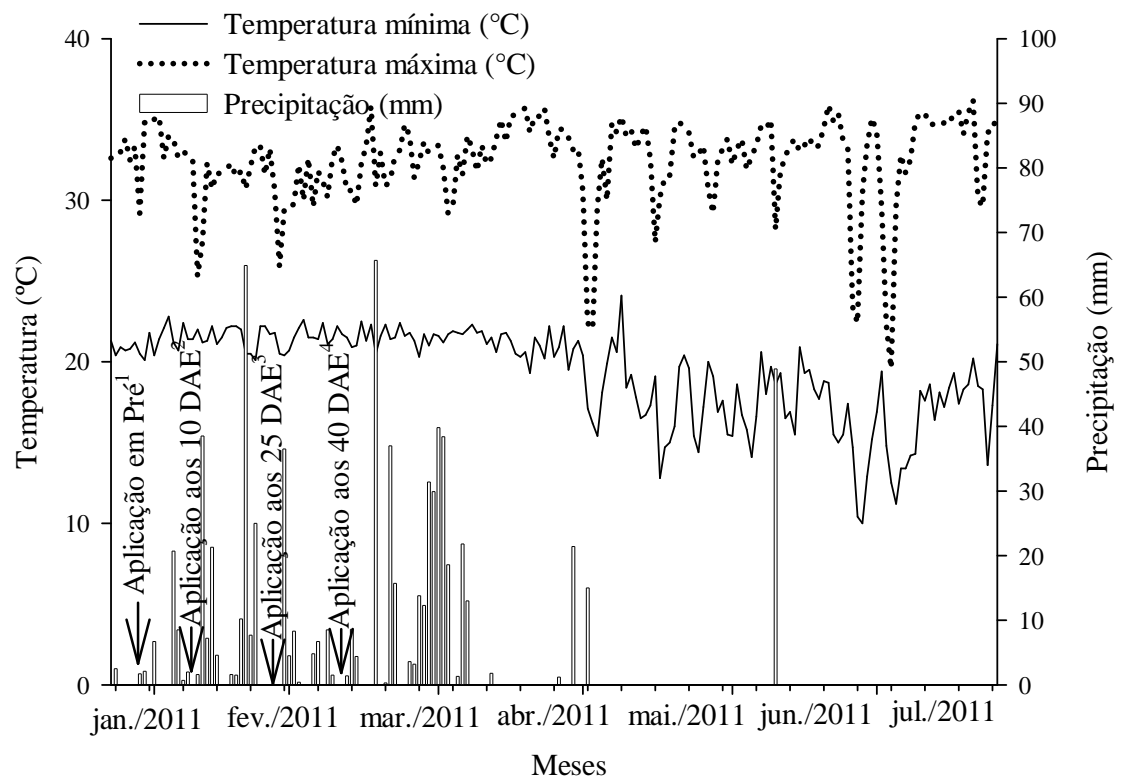

Figura 1. Precipitação pluviométrica $(\mathrm{mm})$, temperatura mínima e máxima $\left({ }^{\circ} \mathrm{C}\right)$ diária do ar entre janeiro a julho de 2011. Diamantino, MT. 1.Tratamentos aplicados em pré-emergência; 2.Tratamentos aplicados aos 10 dias após a emergência da cultura (DAE); 3.Tratamentos aplicados aos 25 DAE; 4. Tratamentos aplicados aos 40 DAE.

Para determinar a eficiência e a seletividade do glufosinato de amônio aplicado isoladamente e em associações com outros herbicidas na cultura do algodão Liberty Link ${ }^{\circledR}$, foi realizado um experimento em delineamento de blocos casualizados com 8 tratamentos e 4 repetições. A cultivar utilizada para o experimento foi a Fiber Max 966 LL.

Variedades de algodão Liberty Link ${ }^{\circledR}$, comercializadas sobre a marca FiberMax, apresentam o gene de resistência ao herbicida glufosinato de amônio (também chamado de Ignite $^{\circledR}, \quad$ Liberty $^{\circledR}, \quad$ Finale $^{\circledR}$ e Rely $\left.^{\circledR}\right)$. O herbicida pode ser aplicado em área total no algodoeiro até 70 dias antes da colheita (Lemon et al., 2004).

O algodão foi semeado no dia 26 de janeiro de 2011. A profundidade de semeadura foi de $3 \mathrm{~cm}$ e as sementes receberam o tratamento padrão empregado pela fazenda, com aplicação do protetor dietholate e do fertilizante foliar a base de acetato de zinco $(4,0 \mathrm{~g}$ e $8,0 \mathrm{~mL}$ para $1,0 \mathrm{~kg}$ de sementes, respectivamente). Foi estabelecida uma quantidade de 10 plantas por metro linear totalizando uma população 222 mil plantas por hectare. A adubação de base de base foi realizada com $145 \mathrm{~kg} \mathrm{ha}^{-1}$ de superfosfato simples, $145 \mathrm{~kg} \mathrm{ha}^{-1}$ de monoamônio fosfato (MAP) granulado e $15 \mathrm{~kg} \mathrm{ha}^{-1}$ de Mn e B. Aos 35 DAE, na adubação foliar foram utilizados 4 $\mathrm{kg} \mathrm{ha}{ }^{-1}$ de MAP purificado e $3 \mathrm{~kg} \mathrm{ha}^{-1}$ de sulfato de manganês, e $7 \mathrm{~kg} \mathrm{ha}^{-1}$ de nitrato de potássio aos 80 DAE. Na adubação de cobertura foram $170 \mathrm{~kg} \mathrm{ha}^{-1}$ de uréia e $150 \mathrm{~kg}$ ha $^{-1}$ de SAM, aos 35 e 50 DAE, respectivamente.

Cada parcela foi constituída de 10 metros de comprimento e 5,4 metros de largura, composta por 12 linhas espaçadas entre si com 0,45 metros. Contudo, apenas as seis linhas centrais foram avaliadas, sendo 
descartados $0,5 \mathrm{~m}$ em cada bordadura inicial e final, além de três linhas das extremidades laterais, totalizando uma área útil de $24,3 \mathrm{~m}^{2}$ por parcela. Os tratamentos foram compostos pelo herbicida glufosinato de amônio associado com fluazifop-p-butil, fomesafen, prometryne, S-metolachor, trifloxisulfuron-sodium que foram aplicados isoladamente e ou em associação, em diferentes épocas conforme a Tabela 2 .

Tabela 2. Tratamentos herbicidas que foram utilizados durante os primeiros 40 dias da cultura, na variedade Fiber Max 966 LL.

\begin{tabular}{|c|c|c|c|c|}
\hline Trat. & $\begin{array}{c}\text { Pré }^{1} \\
\left(\mathrm{~kg} \mathrm{ha}^{-1}\right)\end{array}$ & $\begin{array}{l}10 \mathrm{DAE}^{2} \\
\left(\mathrm{~kg} \mathrm{ha}^{-1}\right)\end{array}$ & $\begin{array}{l}25 \mathrm{DAE}^{3} \\
\left(\mathrm{~kg} \mathrm{ha}^{-1}\right)\end{array}$ & $\begin{array}{l}40 \mathrm{DAE}^{4} \\
\left(\mathrm{~kg} \mathrm{ha}^{-1}\right)\end{array}$ \\
\hline 1 & - & - & - & - \\
\hline 2 & - & $\begin{array}{l}\text { glufosinato de amônio } \\
\qquad(0,50)\end{array}$ & $\begin{array}{l}\text { glufosinato de } \\
\text { amônio } \\
(0,40)\end{array}$ & $\begin{array}{l}\text { glufosinato de } \\
\text { amônio } \\
(0,60)\end{array}$ \\
\hline 3 & - & $\begin{array}{c}\text { glufosinato de amônio } \\
+ \\
\text { S-metolachor } \\
(0,30+0,96)\end{array}$ & $\begin{array}{l}\text { glufosinato de } \\
\text { amônio } \\
(0,40)\end{array}$ & $\begin{array}{c}\text { glufosinato de } \\
\text { amônio + } \\
\text { fluazifop-p-butil } \\
(0,40+0,25)\end{array}$ \\
\hline 4 & $\begin{array}{l}\text { prometryne } \\
\qquad(1,00)\end{array}$ & $\begin{array}{c}\text { S-metolachor } \\
(0,96)\end{array}$ & $\begin{array}{c}\text { glufosinato de } \\
\text { amônio + } \\
\text { trifloxysulfuron- } \\
\text { sodium }(0,30+ \\
0,00225)\end{array}$ & $\begin{array}{l}\text { glufosinato de } \\
\text { amônio } \\
(0,60)\end{array}$ \\
\hline 5 & $\begin{array}{l}\text { prometryne } \\
(1,00)\end{array}$ & $\begin{array}{c}\text { S-metolachor }+ \\
\text { glufosinato de amônio } \\
(0,96+0,30)\end{array}$ & - & $\begin{array}{l}\text { glufosinato de } \\
\text { amônio } \\
(0,60)\end{array}$ \\
\hline 6 & $\begin{array}{l}\text { fomesafen } \\
\qquad(0,50)\end{array}$ & S-metolachor $(0,96)$ & - & $\begin{array}{l}\text { glufosinato de } \\
\text { amônio } \\
(0,60)\end{array}$ \\
\hline 7 & $\begin{array}{c}\text { fomesafen+ } \\
\text { prometryne } \\
(0,50+1,00)\end{array}$ & $\begin{array}{c}\text { S-metolachor }+ \\
\text { glufosinato de amônio } \\
(0,96+0,30)\end{array}$ & - & $\begin{array}{l}\text { glufosinato de } \\
\text { amônio } \\
(0,40)\end{array}$ \\
\hline 8 & $\begin{array}{l}\text { fomesafen+ } \\
\text { prometryne } \\
(0,50+0,75)\end{array}$ & - & $\begin{array}{c}\text { S-metolachor } \\
+ \text { glufosinato de } \\
\text { amônio } \\
(0,96+0,40)\end{array}$ & - \\
\hline
\end{tabular}

1.Tratamentos aplicados em pré-emergência; 2.Tratamentos aplicados aos 10 dias após a emergência da cultura (DAE); 3.Tratamentos aplicados aos 25 DAE; 4.Tratamentos aplicados aos 40 DAE.

As aplicações dos tratamentos de calda equivalente a $200 \mathrm{~L} \mathrm{ha}^{-1}$. Todas as herbicidas foram realizadas aos $0,10,25$ e 40 aplicações foram realizadas respeitando 0 DAE, conforme a Tabela 2. Para tanto, foi mínimo de $50 \%$ de umidade e máximo de utilizado um pulverizador costal de pressão $30^{\circ} \mathrm{C}$. Os tratos culturais foram realizados constante a base de $\mathrm{CO}_{2}$, com pressão de $2 \mathrm{kgf}$ conforme a recomendação técnica adotada pela $\mathrm{cm}^{-2}$, equipado com 5 pontas XR 110.02, fazenda. espaçados em $0,5 \mathrm{~m}$, proporcionando volume 
O levantamento de plantas daninhas foi realizado no momento da colheita. Para esta avaliação foi utilizado uma armação metálica com área de $0,25 \mathrm{~m}^{2}$, lançada quatro vezes ao acaso por parcela.

As avaliações de controle das plantas daninhas e fitointoxicação na cultura foram realizadas visualmente aos 18, 25, 40 e 55 DAE. Foi adotada a escala de notas de $0 \%$ (zero) a $100 \%$ (cem), onde $0 \%$ significa a ausência de controle ou de fitointoxicação, e $100 \%$ a morte de todas as plantas (SBCPD, 1995).

$\mathrm{Na}$ ocasião da colheita do algodão, realizada aos $163 \mathrm{DAE}$, foram avaliados o número de capulhos e a produtividade de algodão em caroço. A avaliação do número de capulhos foi realizada em 10 plantas tomadas aleatoriamente e a determinação da produtividade foi obtida através da colheita dos capulhos presentes na área útil das parcelas $\left(24,3 \mathrm{~m}^{2}\right)$. Posteriormente foi realizada a pesagem do algodão em caroço corrigindo-se para $13 \%$ de umidade e a produtividade estimada em kg ha- ${ }^{-1}$.

Os resultados obtidos foram submetidos à análise de variância pelo teste " $F$ " e às médias foram comparadas pelo teste de Tukey, a $5 \%$ de probabilidade.

\section{Resultados e Discussão}

Todos os tratamentos foram seletivos ao algodoeiro, não se observando sintomas de fitointoxicação em nenhuma das avaliações, inclusive para aqueles tratamentos contemplados com o fomesafen (T6, T7 e T8). $\mathrm{O}$ fomesafen não é recomendado para a cultura do algodoeiro, entretanto, na dose utilizada apresentou excelente resultado em préemergência do algodoeiro.

No momento da colheita, as parcelas provenientes do tratamento testemunha apresentavam as seguintes plantas daninhas em plantas $/ \mathrm{m}^{2}$ : 1 tiririca (Cyperus iria), 1 erva-desanta-luzia (Chamaesyce hirta), 3 trapoeraba
(Commelina benghalensis), 2 corda-de-viola (Ipomoea triloba), 10 apaga-fogo (Alternanthera tenella), 2 poia-branca (Richardia brasiliensis) e 1 caruru (Amaranthus deflexus). Dentre as espécies citadas, houve alta infestação de Alternanthera tenella no tratamento testemunha e nos demais tratamentos com herbicidas houve baixa infestação desta planta daninha, com densidade inferior a 2 plantas $/ \mathrm{m}^{2}$.

Considerando-se que $80 \%$ pode ser o controle mínimo, para prevenir reduções de produtividade das culturas devido à interferência causada pela presença de plantas daninhas nas lavouras (Carvalho et al., 2005), verificou-se que aos $18 \mathrm{DAE}$, com exceção dos tratamentos T2 (glufosinato de amônio) e T3 (glufosinato de amônio e S-metolachlor), estes não precedidos de aplicações em préemergência, todos os demais tratamentos proporcionaram níveis de controle superiores à $80 \%$ (Tabela 3).

Tal resultado ressalta a importância dos tratamentos aplicados em pré-emergência, mesmo quando se emprega variedades resistentes à herbicidas. Resultados semelhantes foram encontrados por Ferri \& Vidal (2003), Dadari \& Kuchinda (2004), Freitas et al. (2006) e Andrade Jr. et al. (2010), em que houve elevada eficiência no controle inicial de plantas daninhas quando foram aplicados herbicidas em pré-emergência do algodoeiro.

$\mathrm{Na}$ avaliação realizada aos $25 \mathrm{DAE}$, todos os tratamentos herbicidas proporcionaram notas superiores a $80 \%$ de controle, com exceção do T2 (glufosinato de amônio) com 77,5\%. O T7 (S-metolachor + glufosinato de amônio) foi significativamente superior ao T2 (glufosinato de amônio) com $93,75 \%$ de controle, mas não diferiu estatisticamente dos demais tratamentos herbicidas (Tabela 3). Apesar do nível de controle do T2 ter elevado aos 25 DAE $(77,5 \%)$, em relação à primeira avaliação aos $18 \mathrm{DAE}(62,5 \%)$, o valor não atingiu o valor 
mínimo aceitável de $80 \%$, o que reforça a aplicados em pré-emergência. importância dos tratamentos herbicidas

Tabela 3. Porcentagens de controle das plantas daninhas que receberam os diferentes tratamentos aos 18, 25, 32, 40 e 55 dias após a emergência (DAE)

\begin{tabular}{|c|c|c|c|c|}
\hline \multirow[t]{2}{*}{ Tratamentos } & \multicolumn{4}{|c|}{ Controle (\%) } \\
\hline & $18 \mathrm{DAE}$ & 25 DAE & 40 DAE & $55 \mathrm{DAE}$ \\
\hline 1 & $0,00 \mathrm{~d}$ & $0,00 \mathrm{c}$ & $0,00 \mathrm{~b}$ & $0,00 \mathrm{~b}$ \\
\hline 2 & $62,50 \mathrm{c}$ & $77,50 \mathrm{~b}$ & $88,75 \mathrm{a}$ & $90,00 \mathrm{a}$ \\
\hline 3 & $68,75 \mathrm{bc}$ & $82,50 \mathrm{ab}$ & $92,50 \mathrm{a}$ & $93,75 \mathrm{a}$ \\
\hline 4 & $83,75 \mathrm{ab}$ & $81,25 \mathrm{ab}$ & $86,25 \mathrm{a}$ & $95,00 \mathrm{a}$ \\
\hline 5 & $90,00 \mathrm{a}$ & $91,25 \mathrm{ab}$ & $86,25 \mathrm{a}$ & $92,50 \mathrm{a}$ \\
\hline 6 & $90,00 \mathrm{a}$ & $87,50 \mathrm{ab}$ & $82,50 \mathrm{a}$ & $92,50 \mathrm{a}$ \\
\hline 7 & $85,00 \mathrm{a}$ & $93,75 \mathrm{a}$ & $91,25 \mathrm{a}$ & $90,00 \mathrm{a}$ \\
\hline 8 & $86,25 \mathrm{a}$ & $83,75 \mathrm{ab}$ & $91,25 \mathrm{a}$ & $91,25 \mathrm{a}$ \\
\hline Média & 80,89 & 85,35 & 88,39 & 92,14 \\
\hline C.V. (\%) & 9,00 & 8,33 & 5,80 & 5,19 \\
\hline $\begin{array}{l}\text { *T1 [testemunha]; T2 } \\
\text { glufosinato de amôni } \\
\text { glufosinato de amôni } \\
\text { prometrine }), \mathrm{B}(0,96 \mathrm{~K} \\
\text { sodium }), \mathrm{D}(0,6 \mathrm{Kg} \mathrm{h} \\
\text { amônio }+0,96 \mathrm{Kg} \text { ha } \\
\mathrm{Kg} \mathrm{ha}^{-1} \mathrm{~S} \text {-metolacho } \\
\text { fomesafen }), \mathrm{B}(0,3 \mathrm{~K} \\
\text { amônio })] ; \mathrm{T} 8[\mathrm{~A}(0,75 \\
\left.\left.\text { ha }^{-1} \mathrm{~S} \text {-metolachor }\right)\right] \text {. } \\
\text { emergência da cultur }\end{array}$ & $\begin{array}{l}\mathrm{Kg} \mathrm{ha}^{-1} \text { glufo } \\
\mathrm{B}\left(0,3 \mathrm{Kg}^{-1} \text { ha }\right. \\
\mathrm{Kg} \mathrm{ha}^{-1} \text { glu } \\
\text { metolachor }) \text {, } \\
\text { sinato de am } \\
\text { lachor }), \mathrm{D}(0, \\
\mathrm{Kg} \mathrm{ha}^{-1} \text { glu } \\
\text { ufosinato de } \\
\text { prometryne + } \\
\text { mentos aplic }\end{array}$ & $\begin{array}{l}\text { amônio), } \mathrm{C}(\mathrm{C} \\
\text { nato de amô } \\
\text { le amônio }+ \\
\text { ha }^{-1} \text { glufosin } \\
5[\mathrm{~A}(1,0 \mathrm{Kg} \\
\text { glufosinato d } \\
\text { de amônio })] \\
+0,96 \mathrm{Kg} \mathrm{l} \\
\mathrm{a}^{-1} \text { fomesafer } \\
\text { pré-semeadı }\end{array}$ & $\begin{array}{l}\text { glufosinato } \\
6 \mathrm{Kg} \mathrm{ha}^{-1} \mathrm{~S}-1 \\
{ }^{-1} \text { fluazifop-p } \\
\text { ônio + } 0,002 \\
\text { metryne }), \mathrm{B}( \\
) ; \mathrm{T} 6[\mathrm{~A}(0,5 \\
1,0 \mathrm{Kg} \mathrm{ha}^{-1} \\
\text { olachor }), \mathrm{D}( \\
\mathrm{Kg} \mathrm{ha}^{-1} \text { glufo } \\
\text { ratamentos }\end{array}$ & $\begin{array}{l}\text { o), } \mathrm{D}\left(0,6 \mathrm{Kg} \mathrm{ha}^{-1}\right. \\
\mathrm{r}), \mathrm{C}\left(0,4 \mathrm{Kg} \mathrm{ha}^{-1}\right. \\
4\left[\mathrm{~A}\left(1,0 \mathrm{Kg} \mathrm{ha}^{-1}\right.\right. \\
\text { trifloxysulfuron- } \\
{ }^{-1} \text { glufosinato de } \\
\text { mesafen }), \mathrm{B}(0,96 \\
\mathrm{e}+0,5 \mathrm{Kg} \mathrm{ha} \\
-1 \text { glufosinato de } \\
\text { mônio }+0,96 \mathrm{Kg} \\
\text { aos } 10 \text { dias após } \\
\text { los aos } 40 \mathrm{DAE} \text {. }\end{array}$ \\
\hline
\end{tabular}

Em estudos realizados por Andrade Jr. et al. (2010) utilizando glufosinato de amônio aplicado aos 15 e $30 \mathrm{DAE}$, em doses de 0,4 e $0,6 \mathrm{~kg} \mathrm{ha}{ }^{-1}$ respectivamente, obtiveram o controle de plantas daninhas superior à $80 \%$, quando foram precedido de tratamentos em pré-emergência com $S$-metolachlor + diuron + trifluralin $\left(1,08+0,8+1,5 \mathrm{~kg} \mathrm{ha}^{-1}\right)$ ou clomazone + diuron + trifluralin $(0,6+0,8+$ $1,5 \mathrm{~kg} \mathrm{ha}^{-1}$ ).

$\mathrm{Na}$ terceira avaliação realizada aos 40 DAE, os dados indicam que não houve diferença significativa entre os tratamentos com herbicidas (Tabela 3), mesmos naqueles onde não houve aplicação de herbicidas em pré-emergência.

$\mathrm{Na}$ avaliação final realizada aos 55 DAE, observou-se que não houve diferença estatística entre os tratamentos com herbicidas (Tabela 3). A partir da análise dos resultados, evidencia-se que todos os tratamentos com herbicidas, indiferentemente do produto utilizado, proporcionaram acima $80 \%$ de controle das plantas daninhas no algodoeiro.

Com relação ao número de capulhos, não houve diferença significativa entre os tratamentos com herbicidas, todos superiores à testemunha (Tabela 4). Apesar das diferenças visuais observadas inicialmente, não houve diferença entre os tratamentos com herbicidas, sendo que, todos os tratamentos com herbicidas proporcionaram incremento superior a $100 \%$ no número de capulhos em relação à testemunha, que não foi capinada. Arantes (2008) ao utilizar tratamentos herbicidas semelhantes aos utilizados neste trabalho, 
empregados em pré-emergência em Argissolo Vermelho distrófico de textura média, também não constatou diferenças no número de capulhos por planta aos 163 DAA na cultivar FMT 701.

Ao avaliar o número de capulhos obtido neste trabalho, evidencia-se que o valor médio $(6,37)$ é baixo, quando comparado os trabalhos de Arantes (2008) e Freitas et al. (2006) que obtiveram em seus melhores tratamentos 7,7 e 11,82 capulhos por planta, respectivamente, com espaçamento entre linhas de 0,9 metros. Tal resultado pode ser atribuído ao baixo índice pluviométrico ocorrido na região, com precipitação média de 4,05 mm (Figura 1), que impossibilitou a abertura de várias maçãs do ponteiro, aliado ao fato de ser uma característica própria do sistema de cultivo adensado, que visa a precocidade e o número máximo de 7 cápsulas (Belot et al., 2010).
$\mathrm{Na}$ Tabela 4, é possível visualizar as médias de produtividade, sendo que não houve diferença significativa entre tratamentos com herbicidas. Por outro lado, Duarte et al. (2008) ressaltaram que as misturas entre $\mathrm{S}$ metolachlor + diuron + oxadiazon $(1,68+1,33$ $+0,39 \mathrm{~kg}$ i.a. $\left.\mathrm{ha}^{-1}\right)$ e pendimethalin + oxadiazon $\left(0,88+0,44 \mathrm{~kg}\right.$ i.a. ha $\left.^{-1}\right)$ utilizadas em pré-emergência, além do controle mecânico, proporcionam as maiores produtividades de algodão em caroço, com a cultivar BRS 187 8H. Dan et al. (2011), estudando a seletividade de herbicidas no algodoeiro, relataram que os tratamentos com clomazone isolado nas doses de 1,00 e $1,25 \mathrm{~kg}$ ha $^{-1}$ ou em associação com $S$-metolachlor $(0,76$ $\left.\mathrm{kg} \mathrm{ha}^{-1}\right)$, diuron $\left(1,50 \mathrm{~kg} \mathrm{ha}^{-1}\right)$, prometryne $\left(1,50 \mathrm{~kg} \mathrm{ha}^{-1}\right)$, alachlor $\left(1,44 \mathrm{~kg} \mathrm{ha}^{-1}\right)$, ou ainda com trifluralin $\left(1,80 \mathrm{~kg} \mathrm{ha}^{-1}\right)$, foram seletivos à cultura do algodão, cultivar NuOpal.

Tabela 4. Número de capulhos aos 163 dias após a emergência (DAE) e produtividade do algodão em caroço. Diamantino-MT. Safra 2010/2011

\begin{tabular}{|c|c|c|}
\hline Tratamentos & $\begin{array}{c}\text { Capulhos } \\
\left(\mathrm{n}^{\mathbf{0}} \text { planta }^{-1}\right)\end{array}$ & $\begin{array}{c}\text { Produtividade } \\
\left(\mathrm{kg} \mathrm{ha}^{-1}\right)\end{array}$ \\
\hline 1 & $3,13 \mathrm{~b}$ & $1007,43 \mathrm{~b}$ \\
\hline 2 & $6,18 \mathrm{a}$ & $3021,77 \mathrm{a}$ \\
\hline 3 & $6,25 \mathrm{a}$ & $3053,22 \mathrm{a}$ \\
\hline 4 & $6,41 \mathrm{a}$ & $3057,88 \mathrm{a}$ \\
\hline 5 & $6,50 \mathrm{a}$ & $3059,26 \mathrm{a}$ \\
\hline 6 & $6,50 \mathrm{a}$ & $3043,97 \mathrm{a}$ \\
\hline 7 & $6,08 \mathrm{a}$ & 3043,97 a \\
\hline 8 & $6,72 \mathrm{a}$ & $3058,76 \mathrm{a}$ \\
\hline Média & 6,37 & 3048,40 \\
\hline C.V. (\%) & 7,00 & 4,25 \\
\hline \multicolumn{3}{|c|}{ 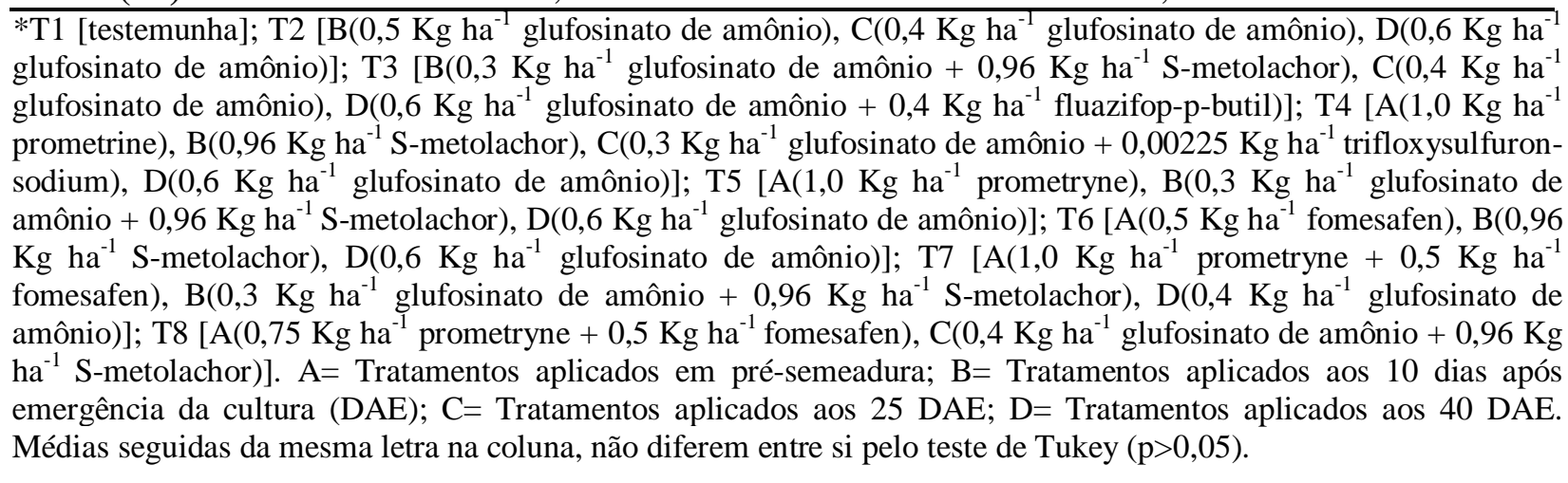 } \\
\hline
\end{tabular}


A partir da análise dos resultados, evidencia que quando o tratamento em préemergência é realizado com eficiência é possível reduzir até duas aplicações em pósemergência sem que haja perdas significativas na produtividade, como foi observado para o tratamento 8. Caso o produtor opte por não realizar a aplicação em pré-emergência é possível evitar perdas na produtividade, desde que utilizado três aplicações sequencias de glufosinato de amônio $\left(0,5 ; 0,4 ; 0,6 \mathrm{~kg} \mathrm{ha}^{-1}\right)$, como verificado no caso do tratamento 2 .

Contudo, ao analisar a produtividade da testemunha fica evidente o potencial de interferência das plantas daninhas na cultura do algodão, visto que as perdas na produtividade foram superiores a $66 \%$, dependendo do tratamento com herbicida (Tabela 4). Estas perdas foram semelhante às observadas por Freitas et al. (2003), que relataram perdas de $45 \%$ na produtividade do algodão em caroço. No entanto, Salgado et al. (2002) ressaltam que a interferência das plantas daninhas na cultivar Delta Opal pode resultar em perdas de até $97 \%$ na produtividade, e para a cultivar de fibra naturalmente colorida 'BRS Safira', Cardoso et al. (2010) encontraram redução de até 91,93\%, quando nenhum controle das plantas daninhas é realizado.

A produtividade média dos tratamentos que foram contemplados com algum tipo de controle com herbicida no manejo das plantas daninhas foi de $3048,40 \mathrm{~kg} \mathrm{ha}^{-1}$, que é relativamente baixa quando comparada a média nacional (3695 kg ha ${ }^{-1}$ e a média do estado (3600 kg ha ${ }^{-1}$ ) para algodão segunda safra "safrinha", conforme os dados da CONAB (2011).

Muitos fatores podem ter influenciado na baixa produtividade do experimento, visto que a cultura do algodoeiro é altamente sensível às condições climáticas, ao ataque de pragas e doenças Dentre estes fatores, a falta de chuvas e a elevada incidência da lagarta rosada observados durante a condução do experimento podem ter influenciado na produtividade final dos diferentes tratamentos.

\section{Conclusões}

Com a aplicação de um tratamento herbicida em pré-emergência é possível reduzir até duas aplicações em pós-emergência, sem que haja perdas significativas na produção. $\mathrm{Na}$ ausência de um tratamento herbicida em préemergência não seja possível é necessário três aplicações sequenciais de glufosinato de amônio $\left(0,5 ; 0,4 ; 0,6 \mathrm{~kg} \mathrm{ha}^{-1}\right)$ aos 10,25 e 40 DAE, para que os resultados sejam semelhantes.

Nas condições em que o experimento foi realizado, todos os tratamentos herbicidas foram seletivos à cultura, não sendo constatadas diferenças significativas no número de capulhos e na produtividade.

\section{Referências}

ANDRADE JR., E.R. et al. Manejo de plantas daninhas no algodoeiro com amoniumglufosinate, usando a cultivar IMA cd 6001 Liberty Link $^{\circledR}$. In: CONGRESSO BRASILEIRO DA CIÊNCIA DAS PLANTAS DANINHAS, 27., 2010, Ribeirão Preto. Anais... Ribeirão Preto: SBCPD, 2010. p.441444.

ANUÁRIO BRASILEIRO DO ALGODÃO. Cenário do algodão. Rio Grande do Sul, 2010. Disponível em: <http://www.anuarios.com.br>. Acesso em: 11 mai. 2011.

ARANTES, J.G.Z. Seletividade de herbicidas aplicados em pré-emergência na cultura do algodoeiro (Gossypium hirsutum L.). 2008. 64 f. Dissertação (Mestrado em Agronomia) Universidade Estadual de Maringá, Maringá, 2008.

BELOT, J.L. et al. Cultivares de algodoeiro herbáceo para o sistema de cultivo adensado. In: BELOT, J.L.; VILELA, P.A. (Eds.). O sistema de cultivo do algodoeiro adensado 
em Mato Grosso: embasamento e primeiros resultados. Cuiabá: Defanti, 2010. p.13-19.

CARDOSO, G.D. et al. Períodos de interferência das plantas daninhas em algodoeiro de fibra colorida "BRS Safira". Revista Ciência Agronômica, v.41, n.3, p.456-462, 2010.

CARVALHO, S.J.P. et al. Curvas de doseresposta para avaliação do controle de fluxos de emergência de plantas daninhas pelo herbicida imazapic. Planta Daninha, v.23, n.3, p.535-542, 2005.

CONAB - Companhia Nacional de Abastecimento. Acompanhamento de safra brasileira: grãos, décimo segundo levantamento, setembro 2011/Companhia Nacional de Abastecimento. Brasília: Conab, 2011.

DADARI, S.A.; KUCHINDA, N.C. Evaluation of some pre- and post-emergence weed control measures on rain fed cotton (Gossypium hirsutum L.) in Nigeria savannah. Crop Protection, v.23, n.5, p.457-461, 2004.

DAN, H.A. et al. Seletividade de clomazone isolado ou em mistura para a cultura do algodoeiro. Planta Daninha, v.29, n.3, p.601607, 2011.

DUARTE, A.E. et al. Seletividade e controle por misturas de herbicidas em algodoeiro herbáceo. Revista Brasileira de Oleaginosas e Fibrosas, v.12, n.1, p.59-67, 2008.

FERRI, M.V.W.; VIDAL, R.A. Controle de plantas daninhas com herbicidas cloroacetamidas em sistemas de plantio convencional e de semeadura direta. Planta Daninha, v.21, n.1, p.131-136, 2003.

FREITAS, R.S. et al. Interferência de plantas daninhas na cultura do algodão. Revista Ceres, v.44, n.256, p.597-603, 2003.

FREITAS, R.S. et al. Manejo de plantas daninhas na cultura do algodoeiro com Smetolachlor e trifloxysulfuron-sodium em sistema de plantio convencional. Planta Daninha, v.24, n.2, p.311-318, 2006.

LEMON, R. et al. Libertyy Link ${ }^{\circledR}$ cotton system. SCS Communications, v.2, n.1, p.1-2, 2004.

SAEG - Sistema para análises estatísticas: versão 7.0, Viçosa: Fundação Arthur Bernardes, 1997.

SALGADO, T.P. et al. Períodos de interferência das plantas daninhas na cultura do algodoeiro (Gossypium hirsutum). Planta Daninha, v.20, n.3, p.373-379, 2002.

SANTOS, G. et al. Seletividade toponômica de herbicidas para a cultura do algodão. Revista Brasileira de Herbicidas, v.10, n.2, p.95-102, 2011.

SBCPD - Sociedade Brasileira da Ciência das Plantas Daninhas. Procedimentos para instalação, avaliação e análise de experimentos com herbicidas. Londrina: SBCPD, 1995. 42p.

WEBSTER, T.M. et al. Cotton planting date affects the critical period of benghal dayflower (Commelina benghalensis) control. Weed Science, v.57, n.1, p.81-86, 2009.

YAMASHITA, O.M. et al. Efeito de doses reduzidas de oxyfluorfen em cultivares de algodoeiro. Planta Daninha, v.26, n.2, p.917921, 2008. 